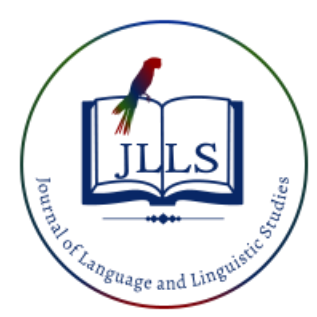

ISSN: 1305-578X

Journal of Language and Linguistic Studies, 17(4), 2154-2165; 2021

\title{
A pragma-linguistic study of suggestive ambiguity in selected political texts
}

\author{
Manal Jasim Muhammad a 1 (iD \\ APA Citation: \\ ${ }^{a}$ University of Baghdad, Iraq \\ Muhammad, M. J. (2021). A pragma-linguistic study of suggestive ambiguity in selected political texts. Journal of Language and Linguistic \\ Studies, 17(4), 2154-2165. Doi: 10.52462/jlls.156 \\ Submission Date:24/05/2021 \\ Acceptance Date:20/08/2021
}

\begin{abstract}
Suggestive ambiguity is a strategy of defense and maneuvering as it provides the speaker both protection and function. To put it differently, it helps the speaker to say whatever he likes and at the same time gives his opponents and friends the interpretation they desire. This is possible due to the flexibility of the linguistic expressions that the speaker uses. To be more clear, the context of situation, peoples' background and world knowledge interact with the significance of the linguistic expressions reaching an allusive situation where two interpretations, positive and negative, are available to the addressees. Such situation enables the addressers to implicate different ideas or messages, accusations, inciting violence, etc. The present study hypothesizes that politicians rely primarily on suggestive ambiguity to fulfill their desires and that the addressees miscomprehend the intended meaning because of the allusive context invested by the addresser. To verify the hypothesis of the study, (10) selected political texts are analyzed in accordance to Walton's (1996) Taxonomy of ambiguity. The analysis reveals that suggestive ambiguity is a strategy of neutralizing stances and covering intentions and it is a way of elevating the political text by bending it to suit different tastes and crosses the boundaries of time and place.
\end{abstract}

Keywords: suggestive ambiguity; imaginary ambiguity; implicit meaning; political language; presupposed meaning

\section{Introduction}

People use language to communicate. Hence, communication may sometimes be complicated, and such complication necessitates it to be flexible. Flexibility is the core of ambiguity as it renders the word, phrase, sentence and even paragraphs to carry multiple legitimate faces of interpretation. It is already taken for granted that there is an incompatibility between words and the things around us in real world, as a result people load words with more than their dictionary meaning to express themselves. The other meaning that is loaded to the words and expressions in language is the hidden meaning which is included in the intended meaning of addressers. This type of meaning requires a context of situation and a smart addressee who can infer the intention behind bending words.

This is the gist of pragmatics, and that is why ambiguity is among the basic premises of pragmatics. Pragmatics requires a context of situation, and the context of situation represents life.

\footnotetext{
${ }^{1}$ Corresponding author.

E-mail address: manal.j@ircoedu.uobaghdad.edu.iq
} 
Life means flexibility which is reflected on language and thus ambiguity is an inherent property of language which adds dynamism to language without which human language becomes monotonous means of communication.

\section{The Notion of Ambiguity}

There is a general consensus among scholars that ambiguity is a matter of two interpretations for a word, a phrase, or a sentence. The word 'report ' is, for example, polysemous which gives different meanings out of context among which are "information about something", "a heavy object" and even "the sound of a Gunshot". Similarly, "light" may mean both the "opposite of heavy" and "dark". Such words are lexically ambiguous and cause confusion on the part of the listener. Ambiguity occurs in phrases and sentences even if none of their constituents is ambiguous. The sentence "the police shot the thief with a gun" is ambiguous as it may mean "A thief with a gun has been shot by the police" or "The police opened fire at the thief".

In this regard "an ambiguous expression has more than one distinct meaning, and almost all expressions can mean different meanings in different contexts" (Cruse, 2006: 10) states. Thus, he insisted that "ambiguity must reserved only for the expression which has more than one established meaning, and this notion is called distinctness of meaning" (ibid). This meaning is important when tackling ambiguity. Consider example (1) (adopted from Cruse, 2006: ibid):

1. a. "My best friend has just had a vasectomy"

b. "My best friend is pregnant"

One easily interprets 'friend' in (1a) as a male friend while in (1b) as a female friend due to the context of situation. Cruse (ibid) argues that ambiguous expressions create no problems since only one interpretation usually fits the context of situation better than the other, which the researcher sharply contradicts in that not all ambiguous expressions can be clearly resolved by appealing to context, people may miss the intended meaning of different unspecified words. In other words, pragmatically ambiguous expressions are quite difficult for most people to grasp without the addresser's intervention.

\section{Types of Ambiguity}

The basic types of ambiguity according to Ullman (1977:159) and Hudson (2000:313) are: lexical ambiguity the elements of which are homonymy, polysemy, homophones and homographs; syntactic ambiguity where one can puzzle the syntactic links of noun phrases resulting in a meaning confusion. The researcher believes that semantic ambiguity and phonetic ambiguity are subsumed under lexical ambiguity in that semantic ambiguity stems from polysemous words and homographs while phonetic ambiguity comes from homonymy and homophones. Walton (1996, cited in Axlsen, 2000: 6) gives a more comprehensive account of ambiguity. He extends the multiplex proposed by the Alexander of Aphrodisiac which consists of only three types namely: potential ambiguity, actual and imaginary ones to six types of ambiguity, realized in the following figure: 


\section{Types of Ambiguity (Walton 1996)}

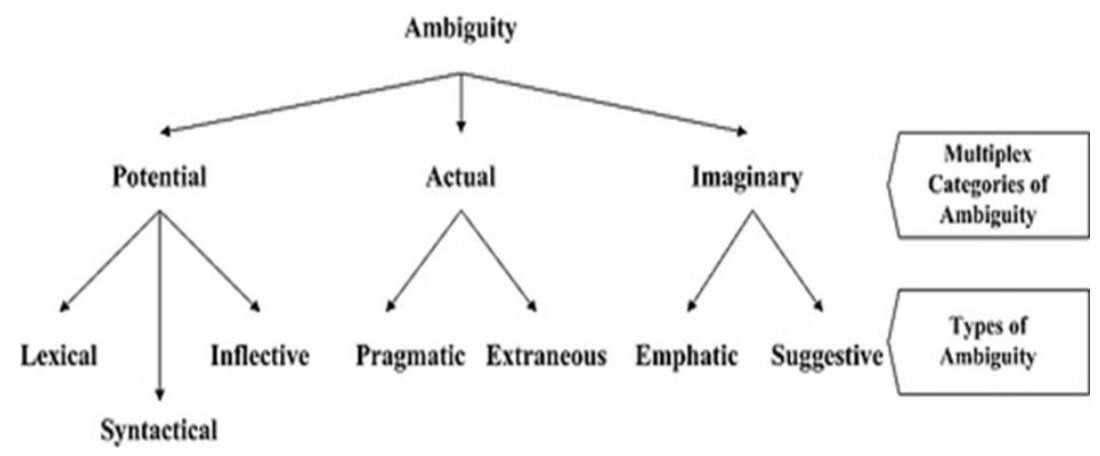

Figure 1. Types of Ambiguity (adopted from Walton's (1996) modified Taxonomy cited in Axlsen, 2000:6-7).

\subsection{Potential ambiguity}

This happens if a word, or even a sentence becomes ambiguous, i.e., prior being contextualized in a sentence or a paragraph. This types occurs when the meaning of the word in the dictionary is polysemous, in this case the word has two different contrasted connotations and when there is a confusion concerning modification. Accordingly, all three types of ambiguity: potential - lexical, syntactic, and inflective.

\subsubsection{The Ambiguity of Lexical}

"Lexical ambiguity occurs when words have more than one established meaning as they are communicated" (Axlsen, 2000:7).

\section{2. "a bank"}

The above example could mean the "bank" of a river or a financial institution (noun), to "bank money" (verb), etc., (Turner 1987 cited in Axlsen, 2000:7). But different sittings or context may aid in mitigating or may solve the ambiguity of the lexical. The researcher, however, contradicts Walton (1996) here, for clearly "the context is invested in bending the texts to give various meanings beyond their dictionary or lexical limits". From another perspective, the ambiguity of the lexical is not confined at all to linguistic expressions which are inherently ambiguous, that is, before being contextualized which is, actually, the case of homonymy and polysemy.

\subsubsection{Syntactic Ambiguity}

"Syntactic ambiguity is a structural or grammatical ambiguity that occurs as a result of confusion concerning the syntactic links between phrases in a specific sentence" (Reilly 1991; Walton 1996 cited in Axlsen, 2000:8). A number of difficulties appeared in applying the structural and grammatical rules to a specific sentence structure causes syntactic ambiguity. For example (3),

(adopted from Axlsen, 2000: 9):

3. "Bob hit the man with the stick".

Example (3) tend to be ambiguous, since the hearer is not sure whether "a man was hit with a stick belonging to Bob, or a man with a stick was struck by Bob" (Axlsen, 2000). Actually, resolve the syntactic ambiguity as we can easily know to whom exactly the stick belongs. 


\subsubsection{Inflective Ambiguity}

Inflective ambiguity is when a word is used twice or more in different senses in the same sentence or paragraph. Walton 1996 and Fowler and Aaron 1998 (both cited in Axlsen, 2000:10) observe that "inflective ambiguity derives from a word in two different senses in one statement", e.g.(4)

4. A report showing the product of our marketing campaign for our accounting software product.

The word 'product' in example (4) gives two different meanings; the first may be a computer whereas the second may be a computer program. However, the researcher argues that inflective ambiguity is not confined to a verb that gives two different senses in one statement, but actually extends to nouns, inflecting them and hence playing on their significance to send a certain message. For example (5) (Proposed by the researcher):

5. We need a governor who Omars us

Omar bin el-Khatab (peace be upon him) was a Muslim caliphate famous of being firm and unbelievably just and hence the intended meaning of the sentence is clear.

\subsection{Actual ambiguity}

Actual ambiguity is a direct ambiguity which occurs when people talk to one another. It arises when sentence, a word or a phrase, even a whole text is clear before being contextualized, yet inside the context they are ambiguous. Thus "the statement lacks enough information to resolve the ambiguity, resulting in a number of legitimate interpretations" (ibid). in this vein, pragmatic and extraneous are the two different types belong to this type.

\subsubsection{Pragmatic Ambiguity}

Axlsen (2000:11) argues that "pragmatic ambiguity arises when the context is not sufficient to capture the intended meaning properly for the statement is allusive, that is, not specific". The missing information according to Copi (1990) "must be inferred, and an example of pragmatic ambiguity is the story of King Croesus and the Oracle of Delphi".

6. King Croesus consulted the Oracle of Delphi before warring with Cyrus of Persia. The Oracle replied that, "If Croesus went to war with Cyrus; he would destroy a mighty kingdom". Delighted, Croesus attacked Persia, and Croesus' army and kingdom were crushed. Croesus complained bitterly to the Oracle's priests, who replied that the Oracle had been entirely right. By going to war with Persia, Croesus had destroyed a mighty kingdom (his own).

Croesus interpreted the Oracle's statement based on the interpretation previously prearranged in his own mind in which considered as his victory, the response he desired while he should have asked him immediately, "Which kingdom?" One can see that the allusive context has enabled the Oracle to deceive Croesus".

Kreidler (1998: 151) states that "the core of pragmatic ambiguity is "un-specifity of reference" that confuses the interpretation and puzzles the addressee". He maintains that "misunderstandings occurs when an addresser and an addressee share the same referent in mind for a definite expression like 'George' or 'the papers', yet one of them is thinking of a different George or some other papers, which, actually, happened with the king Croesus" (Kreidler, 1998: 151), in example 6 when he thought that the mighty kingdom refers to Persia not to his own kingdom. Hence pragmatic ambiguities are a result of the nature of the referring expressions.

\subsubsection{Extraneous Ambiguity}

This type appears in a case when more details given than needed and thus it contrasts pragmatic ambiguity which arises when the information needed to clarify the idea is not sufficient. Clearer 
communication is accomplished when suffice information is used to convey a certain message, (Fowler and Aaron 1998 Cited in Axlsen, 2000:12-13). Moreover, a huge number of words utilized where this huge number of words are not necessary, or in a time that some not needed information is given in the situation or communication which is not the chunk of the message, in this case ambiguity appears. Deleterious details obscure the essential message and contribute in a hazy understanding. In this regard, Fowler \& Aaron (ibid) present the comparative instance below (11), (adopted from Axlsen, 2000: 13)

11. "To perpetuate our endeavor of providing funds for our elderly citizens as we do at the present moment, we will face the exigency of enhanced contributions from all our citizens".

The redundancy of example (11) creates vagueness, then adds to the variety of valid interpretations of the statement. Example (11) exhibits extraneous ambiguity which could be reduced into "We cannot continue to fund Social Security and Medicare for the elderly unless we raise taxes which could be communicated easily due to its clarity and simplicity" (Axslen, 2000).

Another example (12) of extraneous ambiguity illustrative is:

12. "A report of all clients (and their names and addresses only) for the Tax and Business Services department. Some of those clients are our biggest earners, you know" (ibid).

Example (12) is extraneous, involving redundancy, thus, exhibiting an uninformative or misleading sentence compared to the fundamental message. One can argue that extraneous ambiguity creates 'noise' in the communication and consequently a confused understanding, (Axley 1984; Eisenberg \& Phillips 1991; Tankard 1997, cited in Axlsen, 2000:12-13).

\subsection{Imaginary ambiguity}

Imaginary ambiguity arises when a word, a phrase, as sentence or even a paragraph that has a specific meaning appears to be diverse one. While ambiguity of imaginary arises from the explanation of the addressee of the received information. To put it in another way, the addressee has to infer the interpretation investing the available knowledge concerning the issue in question. Two distinct types of ambiguity can be categorized as imaginary ambiguity: emphatic and suggestive.

\subsubsection{Emphatic Ambiguity}

Emphatic Ambiguity is a matter of intonation and stress. When a sentence is said on a specific tone or stressing some parts of it that would contribute directly in changing the significance of the sentence in question. Hence, both the important meaning and also the context are lost. In this regard, Rescher (1964 cited in Axlsen, 2000: 14) has supplied some examples as shown below regarding emphatic:

\section{Democratic credo,}

The deliberated meaning of example (2) is that "Men were created equal' can be changed by stressing the word 'created' (implying that men are no longer so). One can see that stress and hence intonation has yielded a legitimate interpretation" (ibid).

\section{A discount for our good clients.}

Stressing 'good clients' in the above example results in multiple legitimate interpretations, among which are: clients who pay on time or clients who pay good, or may be clients who do not complain the prices, etc.

\subsubsection{Suggestive Ambiguity}

Despite the clarity of the words, phrases, sentences and even a whole text, a single senses varied implications and insinuations which will produce various implications, this one named as suggestive 
ambiguity which the researcher believes it to be suggestively derived from the texts in question. Consider the following examples extracted from a text written by Trow (1905: 14-15) (adopted form Axlsen, 2000:15)

\section{5. 'The Captain was sober all day'}

16. 'The President is now an honest man'

Considerable innuendo exists behind the sentences 'The Captain was sober all day', and 'The President is now an honest man', rendering them quite suggestive. The President's current honesty implies that he was not so. Moreover, Walton (1996) stated that 'the fact that the 'Captain's sobriety', or the 'President's honesty' implies special interpretation which indicates that such a state of affairs is unusual" (Walton, 1996 cited in Axlsen, 2000:15). These statements are suggestively ambiguous. The researcher infers that suggestive ambiguity is a matter of implication and presupposition.

It should be noted here that the researcher will limit the study to examine only imaginary ambiguity, in particular, suggestive one.

\section{Methodology}

\subsection{Data collection}

(10) Selected political texts are chosen from different political speeches and belong to different eras to highlight the pragmatically ambiguous expressions as well as infer the intended meaning of the addresser which is detected as an instance of ambiguity. These political speeches are spoken by Martin Luther king, G. W. Bosh, Tony Blair and Barak Obama respectively. The model that is adopted for the analysis of the study is Walton's Taxonomy (1996 cited in Axslesen, 2000:6-7, see 3.4). Note that the researcher will limit the analysis to only suggestive ambiguity.

\subsection{Data Description}

Political discourse is the formal exchange of reasoned views as to which several alternative courses of action should be taken to solve a societal problem. It is intended to involve all citizens in the making of decisions, persuade others through valid information and logic, and clarify what course of action would be best effective in interpreting events and social issues. Within political discourse, each alternative course of action is expected to a) be strongly advocated, b) receive complete and fair reading and hearing, and c) be critically analyzed to reveal its strengths and weaknesses. For profound understanding, Van Dijk (1998:30) indicates that "political discourse is not a genre, but a class of genres defined by social domains known as that of politics". Thus, speeches or debates of candidates or politicians, cabinet meetings, slogans, political editorials, and propaganda are only examples of the different genres that belong to politics.

Chilton (2004:3 Cited in Wodak, 2004: 210) argues that politics ranges from a very wide concept subsuming every social utterance or any practice of humans to a very narrow view of politics showing it as merely a language communicated by politicians and political institutions. Political language exploits all pragmatic tools for the sake of the indirect or ambiguous propositions. Thus, one can reasonably argue that such ambiguity is totally indented to send certain messages or to avoid convictions.

\subsection{Data Analysis}

\section{Text no.1}

There is no crown without a cross. 


\section{Suggestive Ambiguity}

Martin Luther king (henceforth MLK) deals with the difficulty of reaching goals and fulfilling dreams.

\section{The intention of the speaker}

This sentence means that no freedom could be achieved without suffering. A crown with across is a symbol of the white authority since only they could wear crowns and hold power in the country, in an indication that there is no white authority without a cross which is a token of an outrageous actions and suffering.

\section{Text no.2}

I wish we could get to Easter without going to Good Friday, but history tells us that we got to go by Good Friday before we can get to Easter. That's the long story of freedom, isn't it?

\section{Suggestive Ambiguity}

MLK says that the Easter day cannot be reached unless one goes through Good Friday.

\section{The intention of the speaker}

MLK tries to give his civil right campaign a religious fervor. He implicates that freedom cannot be achieved overnight, but one should go through different steps to accomplish. Easter is a Christian Holiday when Christians celebrate the resurrection of Christ after his crucifixion. Martin Luther sends the message that celebrating freedom, equality, and triumph is not at hand, people must go through sever suffering to fulfill their needs. In other words, he compares Jesus's infliction and triumph over his torturers to theirs; one can sense that MLK compares the Jews who tortured Christ to the 'unjust' American government

\section{Text no. 3}

Ghana tells us that the forces of the universe are on the side of justice. ... Ghana tells me that the forces of the universe are on the side of justice.

\section{Suggestive Ambiguity}

MLK assures people that God sides with the right party, i.e., with justice. So, he provides Ghana as an example which proves that fact.

\section{The intention of the speaker}

MLK implies that God is on the side of the African-Americans since their case is just. He is alluding that the American government represents the other extreme (the unfair side).

\section{Text no.4}

It's going to be one of the most important initiatives that my administration not only discusses but implements.

\section{Suggestive Ambiguity}

Bush addresses people to aid his administration in solving the social and economic problems of USA. He says "my administration not only discusses, but implements".

\section{The intention of the speaker}

G.W. Bush attacked his predecessors, the Democratic Party, in one of his speeches, namely, 'Remarks on the Education Plan Submitted to the Congress on January 23, 2001". He accused them of overlooking his Education reform plans. In this speech 'Faith-Based and Community Initiatives Announcement on January 29, 2001' he said that his plans are to be implemented not only discussed. 
One can see that he puts the phrase "my administration" to tell the audience that he does not only propose but acts.

\section{Text no.5}

It is the story of a new world that became a friend and liberator of the old.

\section{Suggestive ambiguity}

G.W. Bush is delivering his "inaugural address" and telling the addressees about the American accomplishments.

\section{The intention of the speaker}

G.W. Bush reveals his inner feelings and convictions about the old world, i.e., Asia and Africa who are old and backward and are in need for liberation. The word 'friend' attached to the new world represented by Australia, America, and Christian Europe and this implies that the old world, especially the Muslim countries, is the backward ones.

\section{Text no. 6}

In the case of my own Church, the struggle took place very early in my own lifetime just before and during the second Vatican Council. Outdated philosophical ideas were abandoned and the language of human rights adopted. So there is a precedent for those many Muslim leaders deeply concerned at the intellectual impoverishment of their faith and eager in the context of the Arab Spring to make justice the true end of government again.

\section{Suggestive Ambiguity}

Blair refers to his own church and the debate over democracy. He states that the ideas confronting democracy have been removed and replaced by others serving human rights. He calls on Muslim leaders to pursue the same path and define their governments clearly.

\section{The intention of the speaker}

The timing of the speech is quite critical; the context of the Arab Spring reveals that Blair has qualms about Muslim Leaders to adopt "extremist views" in running their countries. Thus one can see that he focus on the "freedom of belief" and the" rights of minorities" and warns from "Islamic extremism" and the perversion from the true faith of Islam. Blair, actually, accuses Islam of having "outdated religious texts" and an "intellectual impoverishment" that endangers human rights and freedom and most importantly wrenching democracy. Thus, he is calling on Muslim leaders, particularly Islamic Brotherhood, that is ascending to power in some Arab countries, to abandon such fanaticism that confront "democracy" and "human rights" according to him, which he labels "outdated philosophical ideas", and" intellectual impoverishment of faith".

\section{Text no. 7}

And in the meantime, I think it's important that we get on with the business. I mean, I was at a primary school earlier. Fantastic new buildings. Great new IT suite. School results improving. I'm here at this school that just in the last few years has come on leaps and bounds, doing fantastically well. We've got the blockade on the Lebanon lifted, today. You know, there are important things going on in the world. And I think I speak for all my Cabinet colleagues when I say that we would prefer to get on with those things because those are the things that really matter and really matter to the country.

\section{Suggestive Ambiguity}

Blair is reviewing the progress in education and development of schools on different levels. This was among his promises to the British community once he becomes the Prime Minister. He says that 
Lebanon has got its blockade removed by a British quest. Then, he reviews some achievements, describing them as things that matter to Britain.

\section{The intention of the speaker}

Blair reminds the Labor party who blames him for his politics, especially, the war on Iraq that puts them in an embarrassing situation in the British community, of what he has done for the country on both the local and the international levels. He reminds them that education progress, the fantastic buildings for schools, the school improving results, and lifting the blockade imposed on Lebanon are the outcomes of his policy which should be regarded as Britain's priorities.

\section{Text no.8}

"I am absolutely convinced that the President of the United States, George Bush, won this election. ... but what I observed as a voter, as a citizen of Illinois four years ago, were troubling evidence of the fact that not every vote was being counted. We continue to see circumstances in which people who believe that they have the right to vote who show up at the polls, still continue to confront the sort of problems that have been documented as taking place, not just in Ohio, but in places all across the country."

\section{Suggestive Ambiguity}

Usually individuals who think that voting is the absolute right for them, who appear up at the surveys, still proceed to go up against the sort of issues that have been recorded as taking put, not only in Ohio, but in the whole country.

\section{The intention of the speaker}

Obama implies that the previous election was not clean and that the votes of many voters (probably implying the votes of African-Americans) were ignored or uncounted intentionally in Ohio and other districts in the country. He alludes at this fact by saying "those who believe that they have the right to vote" to mean the African-Americans. Thus, problems still exist throughout the USA.

\section{Text no.9}

"This is something that we can fix. We have experts on both sides of the aisle who know how to fix it. What we've lacked is the political will"

\section{Suggestive Ambiguity}

"What we've lacked is the political will"

\section{The intention of the speaker}

Obama tells the people that there is a political desire to keep things going on in this 'filibustering way'. He indirectly accuses his Republican opponents of overlooking such problems although having the ability to solve them, because it is in their interest to a blind eye to them.

\section{Text no.10}

The decisions that have been made in Washington these past six years, and the problems that have been ignored, have put our country in a precarious place...Our continued dependence on oil has put our security and our very planet at risk. And we're still mired in a tragic and costly war that should have never been waged.

\section{Suggestive Ambiguity}

Obama highlights the need for a new policy and new decisions that should be made by his administration. He mentions the wrong decisions made by USA government under the presidency of Bush and the serious problems that inflict America as consequences of the previous wrong decisions 
during the past six years. He says that such decisions have caused America many economic problems as well as involving the USA and its security in an unjustifiable war.

\section{The intention of the speaker}

Obama implicates that Bush's administration has mad reckless decisions and hence it responsible of the American current situation. He accuses Bush of waging unaccountable war against Iraq and the speech hints that it was merely for oil that American economy still depends on and that it is the core of the American economic and most crucially security problems.

\subsection{Results and Discussion}

The analysis of the data under investigation reveals that suggestive ambiguity is totally indented to send certain messages or to avoid convictions. All the 10 analyzed texts spoken by the politicians uncover that the frequent use of suggestive ambiguity in political speeches is to sway people unconsciously by suggesting specific ideas or implicating certain messages indirectly to avoid condemnation or other probable accusations. Politician use suggestive ambiguity to condemn, to attack, to uncover many facts to neutralize themselves for certain purposes. In addition suggestive ambiguity creates gaps in political texts so as to drag the addressee to infer the intended meaning himself and reach self-satisfaction.

One could say that Suggestive ambiguity is a function carried by different types of ambiguities when the context is not sufficient to grasp the intended meaning properly. The context sometimes increases the ambiguity of linguistic expressions by suggesting a reasonable meaning to the intended one. This usually happens when interactants have different background knowledge.

In sum, being a device of style in political text, suggestive ambiguity is, actually, an instrument of thought, i.e., it is used to manipulate people, influence them, convince them, push them ,etc., indirectly and may be unconsciously to do some desired actions as the analysis of the study reveals that. One can thus see that suggestive ambiguity is highly used in political texts since such texts are meant to move people in a certain way. In political texts suggestive ambiguity is realized by different pragmatic notions such as conversational implicature and presupposition and of course by different ambiguous expressions. Hence, depending on an adapted model of Walton (1996) (Figure 1), the following table shows respectively the use of suggestive ambiguity in political texts:

Table 1. The Frequency of the use of Suggestive Ambiguity in Political Texts

\begin{tabular}{|c|c|c|c|}
\hline $\begin{array}{c}\text { The Identified } \\
\text { Ambiguity }\end{array}$ & Text No & Frequency & Percentage \\
\hline Suggestive & 1 & 1 & $10 \%$ \\
\hline Suggestive & 2 & 1 & $10 \%$ \\
\hline Suggestive & 3 & 1 & $10 \%$ \\
\hline Suggestive & 4 & 1 & $10 \%$ \\
\hline Suggestive & 5 & 1 & $10 \%$ \\
\hline Suggestive & 6 & 1 & $10 \%$ \\
\hline Suggestive & 7 & 1 & $10 \%$ \\
\hline Suggestive & 8 & 1 & $10 \%$ \\
\hline Suggestive & 9 & 1 & $10 \%$ \\
\hline Suggestive & 10 & & \\
\hline
\end{tabular}




\begin{tabular}{|c|c|c|c|}
\hline & & ? & \\
\hline Total & 10 & 10 & $100 \%$ \\
\hline
\end{tabular}

\section{Conclusion}

Suggestive ambiguous expressions usually carry two interpretations, one of them is positive and the other is negative. The positive is the mask behind which politicians and men of letters hide their intentions. One can thus understand why suggestive ambiguity is the dominant type in political speeches.

Suggestive ambiguity in political speeches is intended to sway people's political opinions and to implicate various innuendoes against opponents. One could say that this type of ambiguity is cunningly employed in settling disputes among nations by making filibustering truces and agreements which satisfy both sides and at the same time neutralizing the international stances. The context sometimes increases the ambiguity by suggesting a reasonable meaning to the intended one. This usually happens when interact ants have different background knowledge.

\section{References}

Axlsen, M. (2000). Information Request Ambiguity and End User Query. MA thesis. University of Queensland.

Bach, K., \& Robert. M. Harnish. (1979). Linguistic Communication speech Acts. Cambridge: MIT Press.

Chilton, P.A. (2004). 'Analysing Political Discourse'. In Wodak, Ruth, (2004). Pragmatics and Critical Discourse Analysis. A cross-disciplinary inquiry. Lancaster University, PP. 210.

Copi, I. M., \& C. Cohen. (1990). 'Introduction to Logic'. Cited in Axlsen. (2000). Information Request Ambiguity and End User Query. MA thesis. University of Queensland.

Cruse, A. (2006). A Glossary of Semantics and Pragmatics. Edinburgh: Edinburgh university press

Diplo. (n.d ). Ambiguity. http://www.diplomacy.edu/language/ambiguity.

Fowler, H. R., \& Aaron, J. E. (1998).'The little Brown Handbook'. Cited in Axlsen. (2000). Information Request Ambiguity and End User Query. MA thesis. University of Queensland.

Fischer, D. H. (1970). 'Historians' Fallacies'. Cited in Axlsen. (2000). Information Request Ambiguity and End User Query. MA thesis. University of Queensland.

Hudson, G. (2000). Essential Introductory Linguistics. Oxford: Blackwell Publishers Ltd.

Kreidler, C. W. (1998). Introducing English Semantics. London: Routledge.

Kooij, J. G. (1971). 'Ambiguity in Natural Language'. Cited in Axlsen. (2000). Information Request Ambiguity and End User Query. MA thesis. University of Queensland.

Rescher, N. (1964). 'Introduction to Logic'. Cited in Axlsen. (2000). Information Request Ambiguity and End User Query. MA thesis. University of Queensland.

Reilly, R. G. (1991). Miscommunication at the Person -Machine Interface. Cited in Axlsen. (2000). Information Request Ambiguity and End User Query. MA thesis. University of Queensland. 
Ryle, G. (1971). 'Collected Papers'. Cited in Axlsen. (2000). Information Request Ambiguity and End User Query. MA thesis. University of Queensland.

Severine, W. J., \& Tankard, J. W. (1997). 'Communication Theories: Origins, Methods, and Uses in the Mass Media'. Cited in Axlsen. (2000). Information Request Ambiguity and End User Query. MA thesis. University of Queensland.

Trow, C. E. (1905). 'The shipmasters of Salem'. Cited in Axlsen. (2000). Information Request Ambiguity and End User Query. MA thesis. University of Queensland.

Turner, G. W. (1987). 'The Australian Concise Oxford Dictionary of current English'. Cited in Axlsen. (2000). Information Request Ambiguity and End User Query. MA thesis. University of Queensland.

Ullman, S. (1977). Semantics: An Introduction to the Science of Meaning. Oxford: Basil Blackwell.

Walton, D. (1996). 'Fallacies Arising from Ambiguity'. Cited in Axlsen. (2000). Information Request Ambiguity and End User Query. MA thesis. University of Queensland.

\section{AUTHOR BIODATA}

Manal Jasim Muhamad is an Assistant Professor in Linguistics at the Department of English, College of Education, University of Baghdad. She has published numerous papers in Discourse analysis, Pragmatics, and Contrastive linguistics in international journals; some of which are indexed in Scopus. Her main interest is Discourse analysis, Contrastive linguistics, Pragmatics, and Semantics. 